\title{
Indomethacin Does Not Diminish the Pulmonary Vascular Response of the Fetus to Increased Oxygen Tension
}

\author{
FREDERICK C. MORIN III, EDMUND A. EGAN, AND WILLIAM $\Upsilon$. NORFLEET
}

The Department of Pediatrics and the Center for Research in Special Environments, Hermann Rahn Laboratory of Environmental Physiology, Department of Physiology, University of Buffalo, SUNY, Buffalo, New York 14214

\begin{abstract}
This study was performed to determine whether prostaglandins play a role in the increase in pulmonary blood flow in the fetal lamb caused by an increase in oxygen tension similar to that occurring at birth. To increase fetal oxygen tension without ventilating the lungs, nine pregnant ewes with chronically instrumented fetuses were exposed to $100 \%$ oxygen at 3 atmospheres absolute pressure for $20 \mathrm{~min}$ in a hyperbaric chamber. This exposure increased pulmonary arterial oxygen tension in the nine fetuses from $20 \pm 1$ to $54 \pm 9$ torr. It increased pulmonary blood flow from fetal to newborn values, $31 \pm$ 3 to $295 \pm 20 \mathrm{ml} / \mathrm{kg} / \mathrm{min}$. It did not change pulmonary arterial pressure, $52 \pm 2$ torr during normoxia and $50 \pm 2$ torr during hyperoxia. Treating five of these fetuses with $3.2 \pm 0.4 \mathrm{mg} / \mathrm{kg}$ of indomethacin during hyperbaric oxygenation did not alter these effects $\left(\mathrm{PO}_{2}=51 \pm 8\right.$ torr, pulmonary blood flow $=283 \pm 13 \mathrm{ml} / \mathrm{kg} / \mathrm{min}$, and pulmonary arterial pressure $=48 \pm 2$ torr . We conclude that the increase in pulmonary blood flow caused by an increase in oxygen tension in the fetus is not maintained by prostaglandins. (Pediatr Res 24:696-700, 1988)
\end{abstract}

Abbreviations

PGD 2 , prostaglandin $\mathrm{D}_{2}$

$\mathrm{PGE}_{2}$, prostaglandin $\mathrm{E}_{2}$

6-keto-PGE 2 , prostaglandin $\mathrm{E}_{2}$

ATA, atmosphere absolute pressure

At birth there is a dramatic decrease in pulmonary vascular resistance and increase in pulmonary blood flow $(1,2)$. The increase in pulmonary blood flow is necessary for the transition from gas exchange by the placenta to gas exchange by the lung. For several reasons, it has been postulated that prostaglandins play an important role in the decrease in pulmonary vascular resistance $(3,4)$. The decrease in pulmonary vascular resistance caused by ventilating the lungs of fetal goats can be markedly attenuated by blocking prostaglandin synthesis with indomethacin (4). Several prostaglandins, e.g. $\mathrm{PGD}_{2}, \mathrm{PGE}_{2}, 6$-keto-PGE 1 , and prostacyclin, are potent dilators of the pulmonary circulation in fetal and newborn goats and lambs (5-10). In addition, prostacyclin has been reported to be produced by the lungs at birth $(2,11,12)$.

Received November 18, 1987; accepted August 5, 1988.

Correspondence Frederick C. Morin III, M.D. Division of Neonatology, Children's Hospital of Buffalo, 219 Bryant Street, Buffalo, NY 14222.

This work was supported by National Institutes of Health Grants HL22552 and 1 PO1 HL34323.
Oxygen is one of the major stimuli decreasing pulmonary vascular resistance at birth $(1,13-15)$. Assali et al., (16) and Heymann et al., (17) isolated the effect of a rise in oxygen tension from the effect of ventilation of the lungs with a gas in acutely instrumented fetal lambs by placing pregnant ewes in a hyperbaric chamber at several atmospheres of pressure. Morin et al. (18) adapted this technique to study chronically instrumented fetal lambs and found that the entire increase in pulmonary blood flow that normally occurs at birth could be produced by an increase in oxygen tension alone.

The current study was performed to determine whether the response of the fetal pulmonary circulation to oxygen is mediated by prostaglandins. We measured the ability of prostaglandin synthesis blockade by indomethacin to diminish the increase in fetal pulmonary blood flow caused by an increase in oxygen tension.

\section{MATERIALS AND METHODS}

Techniques. Nine fetal lambs between 120 and 146 days of gestation were prepared for study. A catheter was passed from the maternal jugular vein into the right atrium for sampling of blood and for induction of anesthesia with $700 \mathrm{mg}$ of sodium thiamylal. Surgery was then performed with the pregnant ewe under halothane anesthesia. The uterus was exposed through an abdominal incision, and the fetal head and neck were delivered through a uterine incision. An incision was made in the fetal neck, and catheters were inserted into the carotid artery for measurement of systemic pressure and via the jugular vein into the superior vena cava for injection of radioactive microspheres. A left thoracotomy was performed, and a catheter was inserted into the main pulmonary artery, proximal to the branching of the right and left pulmonary arteries and the ductus arteriosus, for measurement of pressure; sampling of blood gases and withdrawal of a reference sample during the injection of radioactive microspheres. In each fetus a catheter was attached to the scalp for measurement of amniotic pressure, and the fetus was returned to the uterus. The uterine incision was closed, the catheters brought out through the flank, and the maternal abdominal incision closed. A tracheostomy was also performed on the ewe to control inhaled gases during hyperbaria.

For each measurement of pulmonary blood flow, approximately $8 \times 10^{5}$ spheres $15 \mu$ diameter, labeled with either ${ }^{153} \mathrm{Gd}$, ${ }^{113} \mathrm{Sn},{ }^{103} \mathrm{Ru},{ }^{95} \mathrm{Nb}$, or ${ }^{46} \mathrm{Sc}$, were injected (19). The radioactive microspheres were mixed with $1.5 \mathrm{ml}$ of maternal blood for injection. A $0.1-\mathrm{ml}$ aliquot of this mixture was then counted to determine the radioactivity in the syringe before the injection. The syringe, the barrel of which filled the counting vial, was counted after injection. The difference between preinjection and postinjection syringe counts was injected counts (18). Blood was withdrawn from the pulmonary artery at a rate of approximately 
$2 \mathrm{ml} / \mathrm{min}$ during the period of injection plus $60 \mathrm{~s}$, followed by a rapid $1-\mathrm{ml}$ manual withdrawal to eliminate settling of microspheres in the catheter (18). The actual withdrawal rate was determined by timing the withdrawal and recording the weight increase of the syringe.

During the experiment, the ewe breathed either air or $100 \%$ oxygen. These gases were administered at a flow of 12-16 liters, ambient temperature and pressure, dry/min via a 2-way breathing valve with a small dead space connected to the tracheostomy tube. The inspiration side of the valve was connected to a reservoir bag into which breathing gas was piped from outside the chamber. Another bag on the expiration side allowed the collection of expired gas so as to minimize the fire hazard to the chamber during $100 \%$ oxygen breathing. A sampling tube for a mass spectrometer was connected to the expiration exhaust line, permitting continuous monitoring of the gas. No leaks of chamber air into the system were observed.

Expired gases were measured by a Perkin-Elmer MGA 1100 mass spectrometer. Radioactive counts were measured on a Searle Autogamma counter (G.D. Searle \& Co., Skokie, IL) with a well crystal and automatic compensation for dead time. They were separated by a Nuclear Chicago pulse height analyzer. Fetal vascular pressures and amniotic fluid pressure were measured by Bentley Trantec transducers and recorded on a Gould direct writing recorder. Blood $\mathrm{pH}, \mathrm{PCO}_{2}$, and $\mathrm{PO}_{2}$ were measured by a Radiometer automated blood gas analyzer and reported at $39.5^{\circ}$ C.

Protocol. Three days after surgery, each ewe was placed in a hyperbaric chamber where it was exposed to periods of normoxia and hyperoxia. During normoxia, the ewe breathed air at normal barometric pressure, i.e. 1 ATA. During hyperoxia, the ewe breathed $100 \%$ oxygen at 3.0 ATA. Each experiment began with a 30 -min period of normoxia followed by a 20 -min period of hyperoxia. Five fetuses and their ewes then received indomethacin followed by a 30 -min period of hyperoxia. Each experiment concluded with a 30-min period of normoxia. All indomethacin (Indomethacin sodium trihydrate, Merck, Sharp and Dohme) was dissolved in saline immediately before administration and given intravenously at a dose of $3 \mathrm{mg} / \mathrm{kg}$ to the ewe and $10 \mathrm{mg}$ to the fetus. The resulting fetal dose was $3.2 \pm 0.4 \mathrm{mg} / \mathrm{kg}$ of actual fetal weight.

Fetal heart rate and pulmonary and systemic arterial and amniotic fluid pressures were monitored continuously while the ewe was in the chamber. At the end of each experimental period, maternal and fetal samples for blood gas analysis were drawn, radioactive microspheres were injected into the fetal superior vena cava, and blood was simultaneously withdrawn from the pulmonary arterial catheter. At the end of the experiment, the ewe and fetus were killed with barbiturate. Catheter positions in the ewe and fetus were checked at autopsy. The fetus was weighed as well as its heart, brain, kidneys, spleen, placenta, and lungs. The organs were sliced while wet and placed in tubes filled to uniform height for counting of the radioactivity of the microspheres.
Calculations and data analysis. Amniotic fluid pressure was used as reference pressure, and the vascular pressures were corrected for it. In each fetus, the proportion of microspheres distributed to the individual organs was calculated by dividing the counts in the individual organ by total injected counts. Pulmonary blood flow was calculated by the reference sample technique $(19,20)$. Total pulmonary resistance was calculated as pulmonary arterial pressure/pulmonary blood flow in $\mathrm{ml} / \mathrm{kg} /$ $\min$.

The value of each variable at the end of each period of normoxia or hyperoxia was examined by repeated measures analysis of variance. If it changed significantly, multiple pairwise comparisons of each period and the next period, as well as of the initial and final periods of normoxia, were made by the method of Bonferoni (21). A value of $p \leq 0.05$ was chosen for significance.

\section{RESULTS}

Hyperoxia increased oxygen tension in the right atrium of the ewes from $46 \pm 1$ to $231 \pm 75$ torr $(p \leq 0.05)$. Carbon dioxide tension in the right atrium of the ewes also increased from $33 \pm$ 1 to $40 \pm 2$ torr $(p \leq 0.05)$. In the control fetuses and in the fetuses treated with indomethacin during hyperoxia, pulmonary arterial oxygen tension more than doubled (Table 1). There were small increases in carbon dioxide tension and, therefore, hydrogen ion concentration in both groups of fetuses.

Hyperoxia increased pulmonary blood flow by about 10 -fold in both groups of fetuses (from $32 \pm 11$ to $258 \pm 27 \mathrm{ml} / \mathrm{kg} / \mathrm{min}$ in the control and from $29 \pm 4$ to $324 \pm 23 \mathrm{ml} / \mathrm{kg} / \mathrm{min}$ in the indomethacin-treated fetuses) (Fig. 1). As pulmonary arterial pressure did not change in either group of fetuses, total pulmonary resistance decreased by about 10 -fold. Indomethacin did not diminish the effects of hyperoxia on the pulmonary circulation. Pulmonary arterial pressure did not increase $(50 \pm 3$ to 48 \pm 2 torr), pulmonary blood flow did not decrease (324 \pm 23 to $283 \pm 13 \mathrm{ml} / \mathrm{kg} / \mathrm{min}$ ), and total pulmonary resistance did not increase $(0.16 \pm 0.02$ to $0.17 \pm 0.01$ torr $\mathrm{kg} / \mathrm{min} / \mathrm{ml})$.

Returning the control fetuses to normoxia returned pulmonary arterial pressure, blood flow, and resistance to their values during the initial period of normoxia (Fig. 1). Returning the fetuses treated with indomethacin to normoxia did not return the pulmonary circulatory variables to their initial values. Pulmonary arterial pressure increased to an average of 22 torr more than during the initial period of normoxia (Fig. 1). In association with the increased perfusion pressure, pulmonary blood flow decreased from its value during hyperoxia but remained above its level during the initial period of normoxia (Fig. 1).

Hyperoxia did not close the ductus arteriosus in either group of fetuses. This is demonstrated by the continued delivery of 16$28 \%$ of the initial proportion of microspheres to the organs supplied by the descending aorta (Table 2). These microspheres were delivered to the descending aorta by superior vena caval blood flowing right to left across the ductus arteriosus, not across the foramen ovale. The lack of foramen ovale shunt is demon-

Table 1. The effect of hyperoxia on pulmonary arterial blood gases and $p H$ in four control fetuses and five fetuses treated with indomethacin during hyperoxia*

\begin{tabular}{|c|c|c|c|c|c|c|}
\hline \multirow[b]{2}{*}{ Period } & \multicolumn{3}{|c|}{ Control } & \multicolumn{3}{|c|}{ Indomethacin treated } \\
\hline & $\begin{array}{l}\mathrm{pH} \\
\text { (U) }\end{array}$ & $\begin{array}{l}\mathrm{PCO}_{2} \\
\text { (torr) }\end{array}$ & $\begin{array}{l}\mathrm{PO}_{2} \\
\text { (torr) }\end{array}$ & $\begin{array}{l}\mathrm{pH} \\
\text { (U) }\end{array}$ & $\begin{array}{l}\mathrm{PCO}_{2} \\
\text { (torr) }\end{array}$ & $\begin{array}{l}\mathrm{PO}_{2} \\
\text { (torr) }\end{array}$ \\
\hline Normoxia & $7.34 \pm 0.01$ & $41 \pm 2$ & $20 \pm 2$ & $7.35 \pm 0.02$ & $43 \pm 2$ & $20 \pm 2$ \\
\hline Hyperoxia & $7.27 \pm 0.01$ & $49 \pm 2 \dagger$ & $68 \pm 18 \dagger$ & $7.29 \pm 0.02 \dagger$ & $48 \pm 2 \dagger$ & $42 \pm 5 \dagger$ \\
\hline $\begin{array}{l}\text { Hyperoxia }+ \\
\text { indomethacin }\end{array}$ & & & & $7.32 \pm 0.01$ & $43 \pm 2 \uparrow$ & $51 \pm 8$ \\
\hline Normoxia & $7.34 \pm 0.02$ & $39 \pm 2$ & $22 \pm 2 \dagger$ & $7.29 \pm 0.02 \ddagger$ & $39 \pm 3$ & $22 \pm 2 \dagger$ \\
\hline
\end{tabular}

* Values are mean $\pm \mathrm{SE}$.

$\uparrow$ Significantly different than during preceding period.

$\$$ Significant difference between initial and final periods of normoxia. 
strated by finding only $0.08 \pm 0.02 \%$ of the microspheres in the heart and brain in both groups during all periods but the final period of normoxia in the indomethacin-treated fetuses. There was also no gradient between pulmonary and systemic arterial pressure with this flow of blood across the ductus arteriosus during hyperoxia (Fig. 2).

Indomethacin appeared to constrict the ductus arteriosus, decreasing the proportion of microspheres reaching the descending aorta (Table 2). However, because of the low total pulmonary

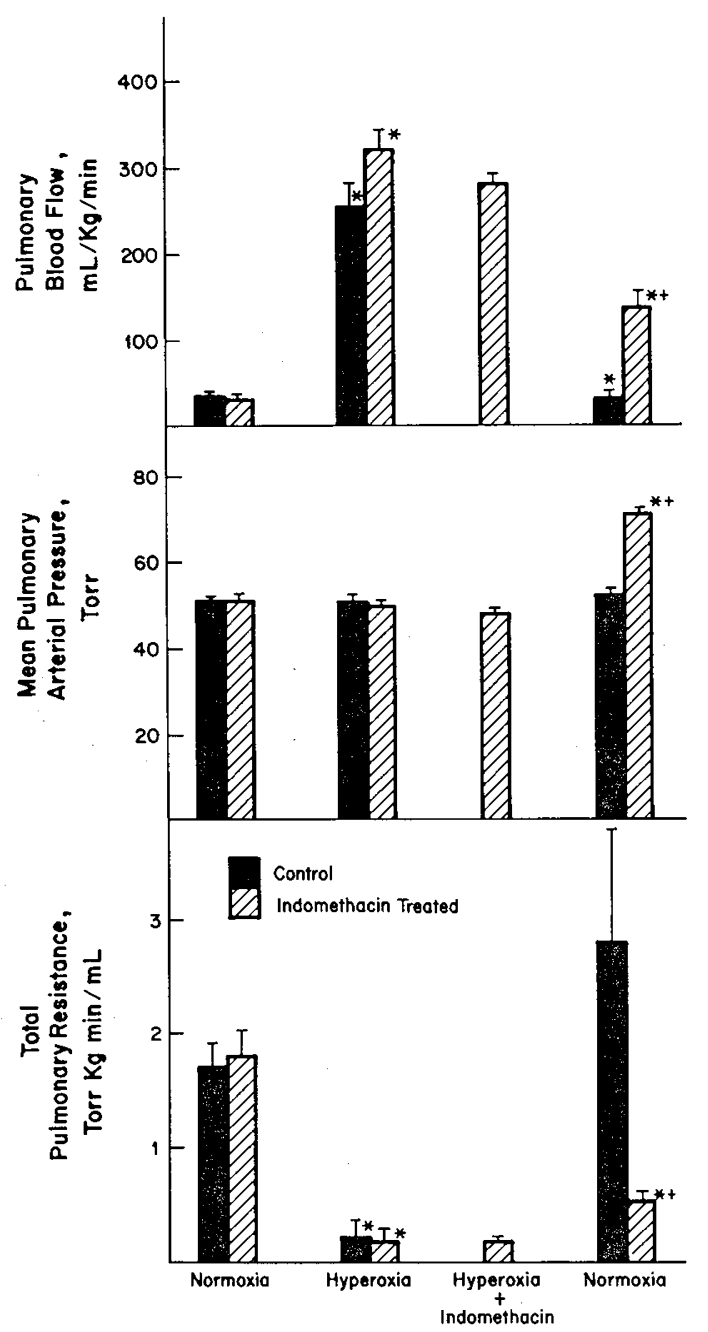

Fig. 1. Pulmonary arterial pressure, blood flow, and resistance in the pulmonary circulation of four control fetal lambs and five fetal lambs treated with indomethacin during hyperoxia. * Significantly different than during the preceding period; ${ }^{+}$significant difference between the initial and final periods of normoxia. resistance, the gradient between pulmonary and systemic arterial pressure did not increase (Fig. 2). The ductus arteriosus remained constricted when the indomethacin-treated fetuses were returned to normoxia. This caused a large pressure gradient from pulmonary to systemic arterial pressure and caused superior vena caval blood to shunt right to left across the foramen ovale, delivering $1.7 \pm 1.2 \%$ of the microspheres to the heart and brain. In contrast, the ductus arteriosus was not constricted in the control fetuses during the return to normoxia. In the controls, the proportion of microspheres delivered to the descending aorta by blood flowing across the ductus arteriosus returned to its initial baseline (Table 2), and there was no pressure gradient from the pulmonary artery to the aorta (Fig. 2).

\section{DISCUSSION}

Morin et al. (18) reported that increasing oxygen tension in the fetal lamb to near newborn values, without ventilating the lungs, increased pulmonary blood flow to newborn values. Our data confirm these findings. At birth, pulmonary blood flow increases by approximately 10 -fold (2), and the pulmonary blood flow of the normal newborn lamb is $290 \mathrm{ml} / \mathrm{kg} / \mathrm{min}$ in a warm environment (22). During hyperoxia, pulmonary blood flow increased 9-fold to $295 \pm 20 \mathrm{ml} / \mathrm{kg} / \mathrm{min}$ (or $1056 \pm 99 \mathrm{ml} / 100$ $\mathrm{g}$ of lung/min) in our nine fetal lambs.

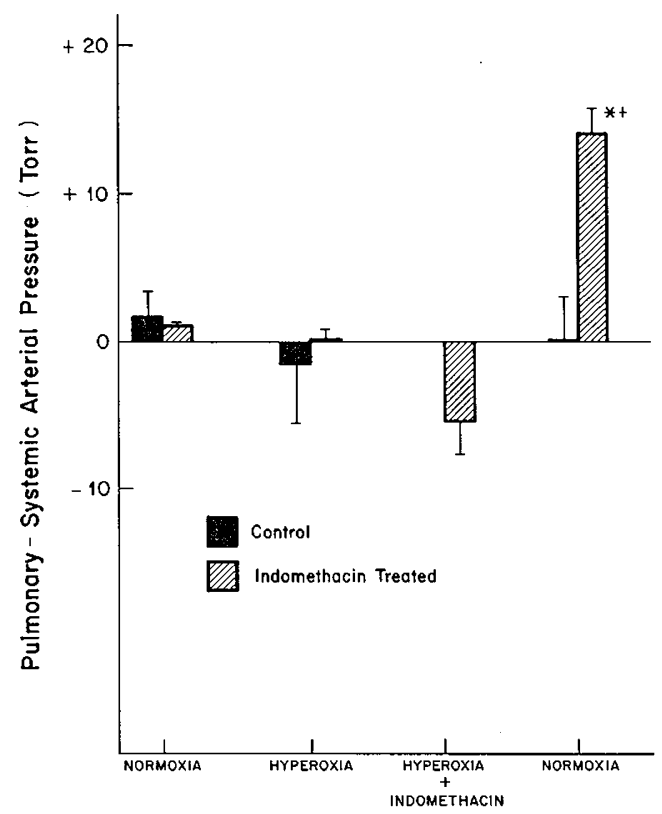

Fig. 2. Pressure gradient from the pulmonary artery to the aorta in four control fetal lambs and five fetal lambs treated with indomethacin during hyperoxia. ${ }^{*}$ Significantly different than during the preceding period; ${ }^{+}$significant difference between the initial and final period of normoxia.

Table 2. Delivery of microspheres to the organs supplied by the descending aorta relative to the delivery during the initial period of normoxia: (organ counts/injected counts) $\div$ (organ counts during initial normoxia/injected counts during initial normoxia)*

\begin{tabular}{|c|c|c|c|c|c|c|}
\hline \multirow[b]{2}{*}{ Period } & \multicolumn{3}{|c|}{ Control $(n=4)$} & \multicolumn{3}{|c|}{ Indomethacin treated $(n=5)$} \\
\hline & Kidneys & Spleen & Placenta & Kidneys & Spleen & Placenta \\
\hline Normoxia & 1 & 1 & 1 & 1 & 1 & 1 \\
\hline Hyperoxia & $0.21 \pm 0.08 \dagger$ & $0.27 \pm 0.10 \dagger$ & $0.28 \pm 0.11 \dagger$ & $0.16 \pm 0.02 \dagger$ & $0.23 \pm 0.02 \dagger$ & $0.20 \pm 0.03 \dagger$ \\
\hline $\begin{array}{l}\text { Hyperoxia }+ \\
\text { indomethacin } \ddagger\end{array}$ & & & & $0.03 \pm 0.01 \dagger$ & $0.08 \pm 0.03$ & $0.05 \pm 0.02 \dagger$ \\
\hline Normoxia & $1.06 \pm 0.18$ & $0.93 \pm 0.15$ & $0.87 \pm 0.10 \dagger$ & $0.32 \pm 0.12 \ddagger$ & $0.14 \pm 0.09+$ & $0.46 \pm 0.18$ \\
\hline
\end{tabular}

* Values are mean $\pm \mathrm{SE}$.

$\dagger$ Significantly different than during the preceding period.

$\ddagger$ Significant difference between the initial and final period of normoxia. 
The increase in pulmonary blood flow during hyperoxia was not due to constriction of the ductus arteriosus. Constricting the ductus arteriosus either mechanically or by inhibiting prostaglandin synthesis can increase pulmonary blood flow to a lesser extent $(23,24)$. However, in that case the increase in blood flow is due to an increase in perfusion pressure and is associated with a pressure gradient from the pulmonary artery to the aorta (23, 24). The maintenance of flow at a lesser level when the indomethacin-treated lambs were returned to normoxia was caused by constriction of the ductus arteriosus. During this period, pulmonary arterial pressure and the gradient from pulmonary to systemic arterial pressure increased substantially. In addition, the high afterload thus placed on the right ventricle caused blood from the superior vena cava to shunt across the foramen ovale to the left atrium. Assuming that left ventricular output is one-third of combined ventricular output (19) and that blood flow to the heart and brain is $6 \%$ of combined ventricular output (25), one can determine that the $1.7 \pm 1.2 \%$ of the microspheres found in the heart and brain represent about $10 \%$ of blood from the superior vena cava shunting across the foramen ovale.

In contrast, during hyperoxia, pulmonary arterial pressure did not increase in our fetuses, and there was a substantial flow of blood across the ductus arteriosus without a pressure gradient. In addition, there was no shunting of blood from the superior vena cava across the foramen ovale. The $0.08 \pm 0.02 \%$ of the microspheres found in the heart and brain in both groups of fetuses during all periods but the final period of normoxia after indomethacin represents less than $1 \%$ of the blood from the superior vena cava shunting across the foramen ovale. This is consistent with the findings of others in the intrauterine fetal lamb $(18,25)$. Similarly, during hyperoxia after indomethacin, pulmonary blood flow remained high, but there was no increase in pulmonary arterial pressure, in gradient from pulmonary to systemic arterial pressure, or in shunting of blood from the superior vena cava across the foramen ovale. Thus, the increase in pulmonary blood flow during hyperoxia and its maintenance during hyperoxia after indomethacin were caused by a decrease in total pulmonary resistance, not by constriction of the ductus arteriosus.

The decrease in total pulmonary resistance and increase in pulmonary blood flow during hyperoxia were caused by the greater than $100 \%$ increase in oxygen tension. Hyperbaria itself does not have these effects in the fetal lamb (18). There was a small increase in the tension of carbon dioxide and decrease in $\mathrm{pH}$. However, respiratory acidosis itself does not decrease pulmonary resistance in the fetal or newborn lamb $(12,13,26,27)$. The increase in carbon dioxide tension may have been due to the Haldane effect as the venous oxygen tension in the ewes during hyperoxia was high enough to saturate hemoglobin (28). A decrease in ventilation by the ewes could also have contributed.

It has frequently been proposed that prostaglandins play an important role in the decrease in pulmonary vascular resistance at birth $(3-6,8,9,29)$. This hypothesis has several types of support. Prostaglandins $\mathrm{D}_{2}, \mathrm{E}_{2}, 6-\mathrm{keto}-\mathrm{E}_{1}$, and $\mathrm{I}_{2}$ (prostacyclin) are potent dilators of the pulmonary circulation in fetal and neonatal lambs and goats $(5-10)$. Prostacyclin is the most likely candidate as it is produced by the lungs with the initiation of breathing at birth $(2,11,12)$. Leffler et al. (4) reported that blocking prostaglandin synthesis with indomethacin markedly attenuated the decrease in pulmonary vascular resistance caused by ventilating the "in situ" perfused lung of the fetal goat. Using a similar preparation, Tyler et al. (30) found that giving indomethacin shortly after the initiation of the ventilation raised pulmonary vascular resistance. Redding et al. (31) reported that blocking prostaglandin synthesis with meclofenamate increased pulmonary vascular resistance in piglets in a manner inversely proportional to age during the 1 st 12 days of life. Surprisingly, we found that indomethacin did not diminish the pulmonary vascular response of the fetal lamb to oxygen. Indomethacin, given during hyperoxia, did not decrease pulmonary blood flow or increase pulmonary arterial pressure or resistance.

Could the lack of effect of indomethacin in our lambs be due to an inadequate dose or an inadequate interval from administration to measurement of its effect? The dose of indomethacin and the interval after the dose were chosen to reproduce the approach used by those reporting effects on the perinatal circulation. Tyler et al. (30) used 1.9 to $2.5 \mathrm{mg} / \mathrm{kg}$ of indomethacin in their premature and mature newborn sheep who were separated from the placenta. Leffler et al. (4) used a dose of $3 \mathrm{mg} / \mathrm{kg}$ in their fetal sheep who were subsequently separated from the placenta. A dose of $3 \mathrm{mg} / \mathrm{kg}$ has been chosen as a dose which blocks whole body synthesis of prostaglandins (32). Because indomethacin crosses the placenta $(4,33)$, and our fetuses would continue to have a placental circulation throughout the experiment, we treated both the ewe and fetus with $3 \mathrm{mg} / \mathrm{kg}$ of indomethacin to prevent losses across the placenta. Tyler $e t$ al. (30), Leffler et al. (4), and Redding et al. (31) each used intervals of 30-45 min after administration to measure the effects of prostaglandin synthesis blockade. In addition, Tyler et al. (30) reported that the effects of indomethacin on the response of the pulmonary circulation of the perinatal lamb to change in oxygen tension were maximal by $30 \mathrm{~min}$. Thus, we chose $30 \mathrm{~min}$.

There are other data indicating this dose and this interval are adequate for blocking prostaglandin synthesis in the lamb. Leffler and Busija reported that cerebrospinal fluid concentrations of 6keto-prostaglandin- $\mathrm{F}_{1 \mathrm{a}}$, the hydrolysis product of prostacyclin, as well as the thromboxane $\mathrm{B}_{2}$ and prostaglandin $\mathrm{E}_{2}$ decreased to negligible levels $30 \mathrm{~min}$ after a $5 \mathrm{mg} / \mathrm{kg}$ dose of indomethacin in the newborn piglet (34). Morin (35) reported that plasma concentrations of 6-keto-prostaglandin- $\mathrm{F}_{1 \mathrm{a}}$ decreased by more than $50 \%$ by $30 \mathrm{~min}$ after a $3 \mathrm{mg} / \mathrm{kg}$ dose of indomethacin in the newborn lamb. In addition, Morin et al. (36) reported, using the same protocol for oxygen and indomethacin administration used in this study, that indomethacin decreased plasma concentrations of 6-keto-prostaglandin- $\mathrm{F}_{1 \mathrm{a}}$ in the fetal lamb by more than $50 \%$ during hyperoxia.

Our results are consistent with the literature showing no major involvement of prostaglandins in the vascular response of the adult lung to hypoxia $(37,38)$. They are also consistent with data on prostacyclin production by the fetus during a rise in oxygen tension produced without ventilation of the lungs. Leffler et al. (39) found that the lungs of the fetal lamb did not produce 6keto-prostaglandin- $F_{1 a}$ when their oxygen tension was raised by "in situ" perfusion from a membrane oxygenator. Morin et al. (36) found that the plasma concentrations of 6-keto-prostaglandin- $\mathrm{F}_{1 \mathrm{a}}$ did not increase when oxygen tension in the chronically instrumented fetal lamb was raised by the hyperbaric chamber technique used in this study.

It is possible that prostaglandins have a role in the increase in pulmonary blood flow at birth unrelated to the maintenance of the response to oxygen. It is conceivable they are involved in the initiation of this response but not its maintenance. Alternatively, they could mediate the response to ventilation of the lungs with a gas. Though an increase in oxygen tension alone can increase fetal pulmonary blood flow to newborn values (18), ventilation of the lungs with a gas which does not change oxygen tension also increases fetal pulmonary blood flow to a lesser extent (12, $40,41)$. Leffler et al. (39) did find that ventilation of the fetal lungs with such a gas caused them to produce 6-keto-prostaglan$\operatorname{din} F_{1 a}$. It is plausible that a response as important as the increase in pulmonary blood flow at birth could be initiated by more than one stimulus and carried out by more than one mechanism. However, the increase in pulmonary blood flow caused by an increase in oxygen tension alone is not diminished by blockade of prostaglandin synthesis.

Acknowledgments. The authors thank Dr. Don Hickey, Bruce Laraway, Dean Marky, Andrew Barth, Ronald Smith, Christine Schurkus, and Lisa LaMonte for their valuable assistance. 


\section{REFERENCES}

1. Rudolph AM 1979 Fetal and neonatal pulmonary circulation. Annu Rev Physiol 41:383-395

2. Leffler CW, Hessler JR, Green RS 1984 The onset of breathing at birth stimulates pulmonary vascular prostacyclin synthesis. Pediatr Res 18:938942

3. Cassin S 1980 Role of the prostaglandins and thromboxanes in the control of the pulmonary circulation in the fetus and newborn. Semin Perinatol 4:101107

4. Leffler CW, Tyler TL, Cassin S 1978 Effect of indomethacin on the pulmonary vascular response to ventilation of fetal goats. Am J Physiol 234:H346-H351

5. Cassin S, Tyler T, Leffler C, Wallis R 1979 Pulmonary and systemic vascular responses of perinatal goats to prostaglandins $E_{1}$ and $E_{2}$. Am $J$ Physiol 236:H828-H832

6. Tod ML, Cassin S 1981 Effects of 6-keto-prostaglandin $E_{1}$ on perinatal pulmonary vascular resistance. Proc Soc Exp Biol Med 166:148-152.

7. Leffler CW, Hessler JR 1979 Pulmonary and systemic vascular effects of exogenous prostaglandin $I_{2}$ in fetal lambs. Europ J Pharmacol 54:37-42

8. Green R, Rojas J, Sundell H 1979 Pulmonary vascular response to prostacyclin in fetal lambs. Prostaglandins 18:927-934

9. Soifer SJ, Morin FC, Heymann MA 1982 Prostaglandin $\mathrm{D}_{2}$ reverses induced pulmonary hypertension in the newborn lamb. J Pediatr 100:458-463

10. Lock JE, Olley PM, Coceani F 1980 Direct pulmonary vascular responses to prostaglandins in the conscious newborn lamb. Am J Physiol 238:H631638

11. Leffler CW, Hessler JR 1981 Perinatal pulmonary prostaglandin production. Am J Physiol 241:H756-H759

12. Davidson D 1988 Pulmonary hemodynamics at birth: Effect of acute cyclooxygenase inhibition in lambs. J Appl Physiol 64:1676-1682

13. Cassin S, Dawes GS, Mott JC, Ross BB, Strang LB 1964 The vascular resistance of foetal and newly ventilated lung of the lamb. J Physiol (London) 171:6179

14. Cook CD, Drinker PA, Jacobson HN, Levinson H, Strang LB 1963 Control of pulmonary blood flow in the foetal and newly born lamb. J Physiol (Lond) 169:10-29

15. Lauer RM, Evans JA, Aoki H, Kittle CF 1965 Factors controlling pulmonary vascular resistance in fetal lambs. J Pediatr 67:568-577

16. Assali NS, Kirschbaum TH, Dilts PV 1968 Effects of hyperbaric oxygen on uteroplacental and fetal circulation. Circ Res 22:573-588

17. Heymann MA, Rudolph AM, Nies AS, Melmon KL 1969 Bradykinin production associated with oxygenation of the fetal lamb. Circ Res 25:521-534

18. Morin III FC, Egan EA, Ferguson W, Lundgren CEG 1988 The development of pulmonary vascular response to oxygen. Am J Physiol 23:H542-H546

19. Heymann MA, Creasy RK, Rudolph AM 1973 Quantitation of blood flow patterns in the foetal lamb in utero. In: Comline KS, Cross KW, Dawes GS Nathanielsz PW (eds) Foetal and Neonatal Physiology: Proceedings of the Sir Joseph Barcroft Cententary Symposium. Cambridge University Press, Cambridge, pp 129-135

20. Heymann MA, Payne BD, Hoffman JIE, Rudolph AM 1977 Blood flow measurements with radionuclide-labeled particles. Prog Cardiovasc Dis $20: 55-77$
21. Wallenstein S, Zucker CL, Fleiss JL 1980 Some statistical methods useful in circulation research. Circ Res 47:1-9

22. Sidi D, Kuipers JRG, Heymann MA, Rudolph AM 1983 Effects of ambient temperature on oxygen consumption and the circulation in newborn lambs at rest and during hypoxemia. Pediatr Res 17:254-258

23. Morin FC, III, Egan EA The effect of closing the ductus arteriosus on the pulmonary circulation of the fetal lamb. $J$ Devel Physiol, (in press)

24. Heymann MA and Rudolph AM 1976 Effects of acetylsalicylic acid on the ductus arteriosus and circulation in the fetal lambs in utero. Cir Res 38:418422

25. Rudolph AM and Heymann MA 1970 Circulatory changes during growth in the fetal lamb. Cir Res 26:289-299

26. Johnson GH, Kirschbaum TH, Brinkman CR, III, Assali NS 1971 Effects of acid, base, and hypertonicity on fetal and neonatal cardiovascular hemodynamics. Am J Physiol 220:1798-1807

27. Rosenberg AA, Koehler RC and Jones Jr MD 1984 Distribution of cardiac output in fetal and neonatal lambs with acute respiratory acidosis. Pediat Res 18:731-735

28. Haldane JS, Priestly JG 1935 Respiration. Yale University Press. New Haven, CT

29. Heymann MA 1987 Postnatal regulation of the pulmonary circulation: A role for lipid mediators? Am Rev Resp Dis 136:222-224

30. Tyler T, Wallis R, Leffler C, Cassin S 1975 The effects of indomethacin on the pulmonary vascular response to hypoxia in the premature and mature newborn goat. Proc Soc Exp Biol Med 150:695-698

31. Redding GJ, McMurtry I, Reeves JT 1984 Effects of meclofenamate on pulmonary vascular resistance correlate with postnatal age in young piglets. Pediatr Res 18:579-583

32. Lock JE, Olley PM, Soldin S, Coceani F 1980 Indomethacin induced pulmonary vasoconstriction in the conscious newborn lamb. Am $\mathbf{J}$ Physiol 238:H639-H651

33. Momma K, Takoa A 1987 In vivo constriction of the ductus arteriosus by nosterodal antiinflammatory drugs in near-term and pre-term fetal rats. Pediatr Res 22:567-572

34. Leffler CW, Busija DW 1985 Prostanoids in cortical subarachnoid cerebrospinal fluid and pial diameter in newborn pigs. Circ Res 57:689-694

35. Morin FC, III 1986 Hyperventilation, alkalosis, prostaglandins and the pulmonary circulation of the newborn. J Appl Physiol 61:2088-2094

36. Morin FC, Egan EA, Lundgren CEG, Swartz DD 1988 Prostacyclin does not change during an oxygen induced increase in pulmonary blood flow in the fetal lamb. Prostaglandins Leukotrienes Essential Fatty Acids 32:139-144

37. Weir ER, McMurtry IF, Tucker A, Reeves JT, Grover RF 1976 Prostaglandin syntheses inhibitors do not decrease hypoxic pulmonary vasoconstriction. J Appl Physiol 41:714-718

38. Vaage J, Bjertnaes L, Hauge A 1975 The pulmonary vasoconstrictor response to hypoxia: Effect of inhibitors of prostaglandin biosynthesis. Acta Physiol Scand 95:95-101

39. Leffler CW, Hessler JR, Green RS 1984 Mechanism of stimulation of pulmonary prostacyclin synthesis at birth. Prostaglandins 28:877-887

40. Enhorning $G$ Adams FH Norman A 1966 Effect of lung expansion on the fetal lamb circulation. Acta Paediatr Scand 55:441-451

41. Iwamoto HS, Teitel D, Rudolph AM 1987 Effects of birth-related events on blood flow distribution. Pediatr Res 22:634-640 